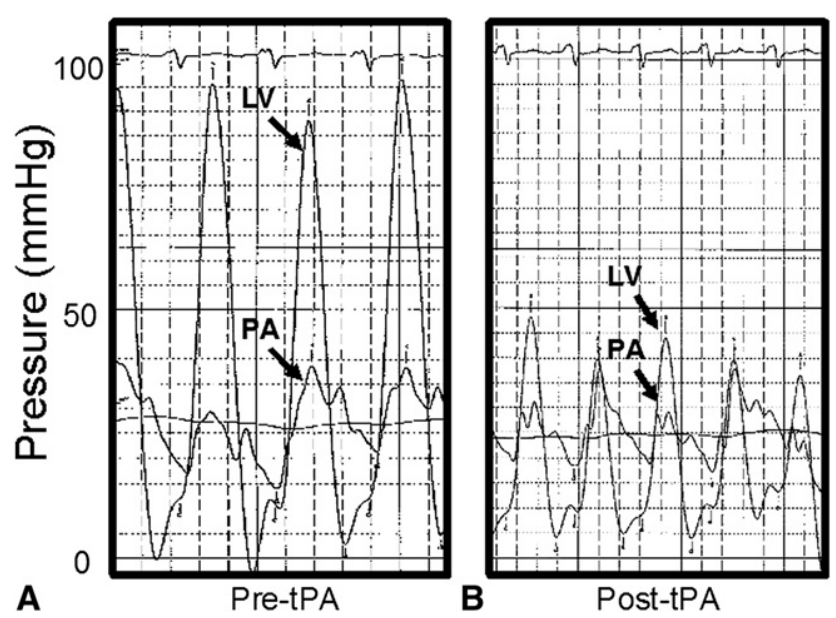

FIGURE 2. Left ventricular $(L V)$ and pulmonary artery $(P A)$ hemodynamic tracings before (A) and after (B) thrombolysis.

intracavitary thrombolysis may be the reduced dose of drug required because of direct application to the LVAD inflow cannula. As nonpulsatile LVADs are increasingly applied in the management of end-stage heart failure, standardization of the percutaneous management of device thrombosis may be necessary.

\section{References}

1. Slaughter MS, Rogers JG, Milano CA, Russell SD, Conte JV, Feldman D, et al. Advanced heart failure treated with continuous-flow left ventricular assist device. N Engl J Med. 2009;361:2241-51.

2. Pagani FD, Miller LW, Russell SD, Aaronson KD, John R, Boyle AJ, et al. Extended mechanical circulatory support with a continuous-flow rotary left ventricular assist device. J Am Coll Cardiol. 2009;54:312-21.

3. Delgado R 3rd, Frazier OH, Myers TJ, Gregoric ID, Robertson K, Shah NA, et al. Direct thrombolytic therapy for intraventricular thrombosis in patients with the Jarvik 2000 left ventricular assist device. J Heart Lung Transplant. 2005;24:231-3.

4. Rothenburger M, Wilhelm MJ, Hammel D, Schmidt C, Tjan TD, Böcker D, et al. Treatment of thrombus formation associated with the MicroMed DeBakey VAD using recombinant tissue plasminogen activator. Circulation. 2002;106(12 Suppl. 1):I189-92.

5. Thomas MD, Wood C, Lovett M, Dembo L, O'Driscoll G. Successful treatment of rotary pump thrombus with the glycoprotein IIb/IIIa inhibitor tirofiban. J Heart Lung Transplant. 2008;27:925-7.

\title{
Video-assisted thoracoscopic surgical tracheobronchoplasty for tracheobronchomalacia
}

\author{
David G. Tse, MD, ${ }^{a}$ Sukgu M. Han, MD, ${ }^{a}$ Burawit Charuworn, MD, ${ }^{\mathrm{b}}$ and Eric S. Kaufer, MD, \\ Los Angeles, Calif
}

The surgical treatment of tracheobronchomalacia has continued to evolve since the operative interventions for tracheomalacia described in 1954 by Nissen. ${ }^{1}$ Recent experience with polypropylene mesh in the management of tracheobronchomalacia has demonstrated satisfactory long-term results. ${ }^{2,3}$ We report 2 cases of video-assisted thoracoscopic surgical tracheobronchoplasty combined

From the Divisions of Thoracic Surgery ${ }^{\mathrm{a}}$ and Pulmonary Medicine, ${ }^{\mathrm{b}}$ Kaiser Permanente Medical Center, Los Angeles, Calif.

Disclosures: Authors have nothing to disclose with regard to commercial support.

Received for publication Sept 21, 2010; revisions received Nov 10, 2010; accepted for publication Nov 23, 2010; available ahead of print Jan 31, 2011.

Address for reprints: David G. Tse, MD, Department of Thoracic Surgery, Kaiser Permanente Medical Center, 6041 Cadillac Ave, Los Angeles, CA 90034 (E-mail: david.g.tse@kp.org).

J Thorac Cardiovasc Surg 2011;142:714-6

$0022-5223 / \$ 36.00$

Copyright (C) 2011 by The American Association for Thoracic Surgery

doi:10.1016/j.jtcvs.2010.11.037 with airway stent placement for the treatment of tracheobronchomalacia.

\section{CLINICAL SUMMARIES \\ Patient 1}

A 56-year-old man with a history of severe chronic obstructive pulmonary disease had undergone 6 hospitalizations for respiratory failure during the previous year. $\mathrm{He}$ reported decreased exercise tolerance and inability to clear airway secretions. Results of pulmonary function tests were suggestive of intrathoracic large airway obstruction. Flexible bronchoscopy demonstrated severe tracheobronchomalacia with collapse of the entire left mainstem bronchus. Dynamic computed tomographic chest scan showed expiratory collapse of the central airways (Figure 1). A right video-assisted thoracoscopic surgical tracheobronchoplasty of the trachea, right mainstem bronchus and bronchus intermedius was performed with polypropylene mesh. The 


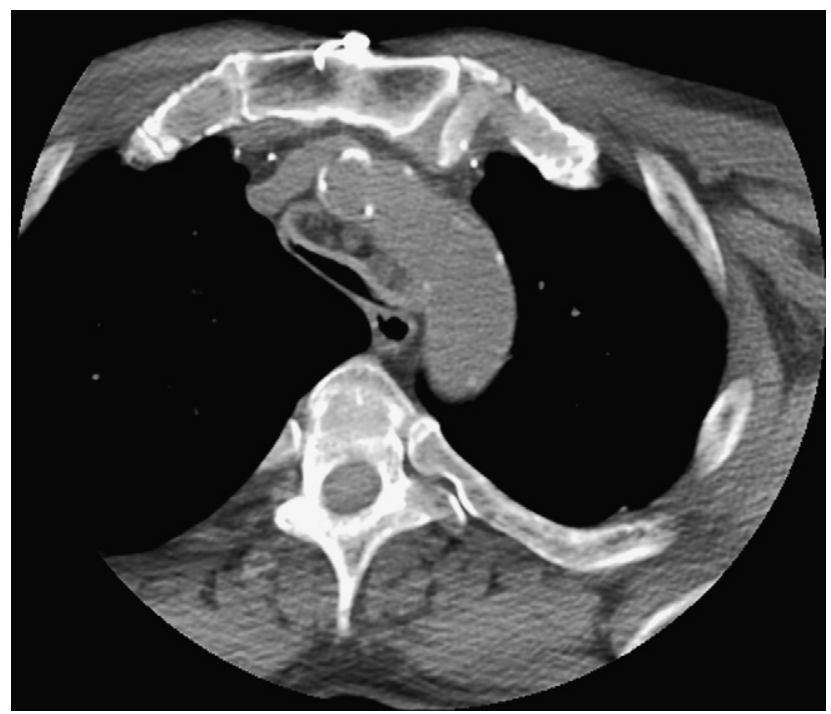

FIGURE 1. Computed tomographic scan shows expiratory collapse of distal trachea.

left mainstem bronchus, which lacked substantial cartilage structure, was not amenable to mesh repair and was treated with a nitinol Ultraflex Microvasive noncovered stent (Boston Scientific, Natick, Mass). The patient was discharged on postoperative day 2. Subsequent pulmonary function test results revealed improvement in forced expiratory volume in 1 second of $300 \mathrm{~mL}$ and midexpiratory flows (forced expiratory flow $25 \%-75 \%$ ) from 0.38 to $1.01 \mathrm{~L} / \mathrm{s}$. He remains well 4 months after the procedure.

\section{Patient 2}

An 89-year-old woman with a history of severe chronic obstructive pulmonary disease, severe aortic stenosis, diabetes, and obesity was hospitalized for respiratory failure. A computed tomographic chest scan showed diffuse anterior prolapse of the posterior membranous tracheal wall on expiration (Figure 2). Flexible bronchoscopy revealed severe tracheobronchomalacia with exhalation. The patient underwent a right video-assisted thoracoscopic surgical tracheobronchoplasty of the trachea and right mainstem bronchus with polypropylene mesh. Nitinol Ultraflex Microvasive noncovered stents (Boston Scientific) were inserted into the left mainstem bronchus and bronchus intermedius, because there was insufficient cartilage structure of the left mainstem bronchus to sustain mesh repair and the bronchus intermedius was found to be malacic on postprocedure bronchoscopy. The patient was extubated on postoperative day 2 and discharged to a rehabilitation facility on postoperative day 6 . Her sensation of suffocation had resolved, and she was able to ambulate short distances 1 month after the procedure.

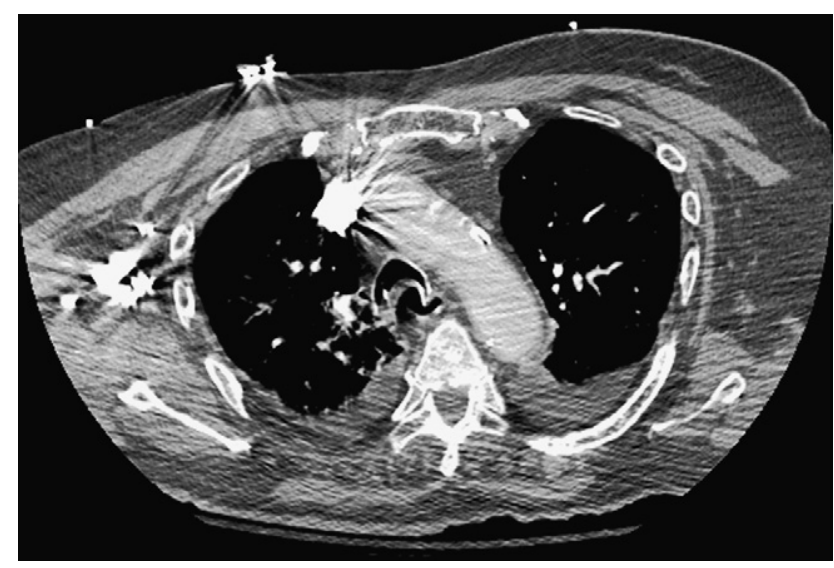

FIGURE 2. Computed tomographic scan shows anterior prolapse of posterior membranous tracheal wall.

\section{DISCUSSION}

The successful treatment of tracheobronchomalacia is predicated on confirmatory studies. It is essential to distinguish patients whose symptoms arise from pathologic central airway compliance from those whose symptoms arise from progression of peripheral airway disease. A trial of temporary airway stabilization with 1 or more silicone stents can improve patient selection for tracheobronchoplasty. Wright and colleagues ${ }^{2}$ have described their experience with polypropylene mesh to stabilize the central airways through a right posterolateral thoracotomy.

Our thoracoscopic technique incorporates polypropylene mesh to stabilize the cartilaginous rings and plicate the redundant posterior membranous wall. Mesh size is determined by the preoperative inspiratory computed tomographic images of the central airways. A size 35 left-sided double-lumen endotracheal tube is preferred to isolate the right lung. Through the right hemithorax, the camera port to accommodate a $30^{\circ}$ thoracoscope is placed in the 7 th intercostal space in the posterior axillary line. Additional $1-\mathrm{cm}$ incisions are placed in the 6th intercostal space in the anterior axillary line and the 7th intercostal space inferior to the auscultatory triangle. A 2-cm incision is placed in the 4 th intercostal space anterior to the latissimus dorsi. The posterior trachea is exposed from the thoracic inlet to the carina, and the azygos vein is divided. After deflation of the tracheal cuff, a row of four 4-0 polypropylene sutures is placed with an endoscopic needle driver, securing the polypropylene mesh to the proximal posterior tracheal wall from a lateral to medial direction. The sutures, which are tied sequentially, incorporate the edges of the cartilaginous ring and plicate the posterior membranous wall. The latter effect is accomplished by central partial thickness vertical mattress sutures. Rows are placed $1 \mathrm{~cm}$ apart, ending at the carina. Bronchoplasty is performed similarly. The adequacy 
of repair is assessed by the application of suction by means of a flexible bronchoscope through a single-lumen endotracheal tube with observation of the major airways. Bronchial airways that are refractory or not amenable to mesh repair are addressed immediately with an airway stent. Nitinol stents have provided durable results in appropriately selected patients in our experience, as well as those of others, ${ }^{4}$ but require careful follow-up because of the potential for complications such as stent fracture, perforation, obstruction, and migration.

Video-assisted thoracoscopic surgical tracheobronchoplasty provides a progressive alternative for central airway stabilization. Minimizing tissue trauma is advantageous, especially for patients with chronic obstructive pulmonary disease in whom parenchymal disease and diaphragmatic and chest wall dysfunction limit postoperative adaptive changes.

\section{References}

1. Nissen R. Tracheoplastik zur beseitigung der erschlaffung des membranosen teils der intrathorakalen luftrohre. Schweiz Med Wochenschr. 1954;84:219-21.

2. Wright CD, Grillo HC, Hammoud ZT, Wain JC, Gaissert HA, Zaydfudim V, et al. Tracheoplasty for expiratory collapse of central airways. Ann Thorac Surg. 2005; 80:259-66.

3. Majid A, Gurerrero J, Gangadharan S, Feller-Kopman D, Boiselle P, DeCamp M, et al. Tracheobronchoplasty for severe tracheobronchomalacia: a prospective outcome analysis. Chest. 2008;134:801-7.

4. Husain SA, Finch D, Ahmed M, Morgan A, Hetzel MR. Long-term follow-up of ultraflex metallic stents in benign and malignant central airway obstruction. Ann Thorac Surg. 2007;83:1251-6.

\title{
Anterior leaflet augmentation for ischemic mitral regurgitation in patients with anomalous left coronary artery from the pulmonary artery and preserved left ventricular function
}

\author{
Michael H. Hines, MD, ${ }^{a}$ Edward H. Kincaid, MD, ${ }^{a}$ Amanda L. Cook, MD, ${ }^{\mathrm{b}}$ and Neal D. Kon, MD, ${ }^{\mathrm{a}}$ \\ Winston-Salem, NC
}

Anomalous left coronary artery from the pulmonary artery (ALCAPA) is a rare congenital defect that usually presents in infancy with poor left ventricular (LV) function and significant mitral regurgitation (MR). Correction of the anomaly with reimplantation, intra-arterial baffling, or interposition grafting usually leads to improved LV function and thereby reduction of the MR. We present 3 unusual cases of left coronary artery anomalies in patients with preserved LV function but with severe MR and discuss a technique and rationale for treatment.

\section{CLINICAL SUMMARY \\ Patient 1}

A 2-week-old given a diagnosis of ALCAPA and severe MR but with normal LV function underwent reimplantation of the anomalous coronary artery. She was weaned easily

From the Department of Cardiothoracic Surgery ${ }^{\mathrm{a}}$ and the Section of Pediatric Cardiology, ${ }^{\mathrm{b}}$ Department of Pediatrics, Wake Forest University School of Medicine, Winston-Salem, NC

Disclosures: Authors have nothing to disclose with regard to commercial support. Received for publication July 27, 2010; revisions received Nov 21, 2010; accepted for publication Jan 17, 2011; available ahead of print Feb 21, 2011.

Address for reprints: Michael H. Hines, MD, Cardiothoracic Surgery, WFUSM Medical Center Blvd, Winston-Salem, NC 27157 (E-mail: mhinesmd@ gmail.com).

J Thorac Cardiovasc Surg 2011;142:716-8

$0022-5223 / \$ 36.00$

Copyright $($ c 2011 by The American Association for Thoracic Surgery

doi:10.1016/j.jtcvs.2011.01.025 from cardiopulmonary bypass and had an uncomplicated course, despite persistent MR. Over the next 4 months, she had continued poor weight gain, tachypnea, and feeding difficulty. The MR remained severe, with poor central coaptation, tethering of the anterior leaflet, and worsened left atrial enlargement (Figure 1, $A$ and $B$ ) At 8 months of age, she underwent anterior leaflet augmentation with a mitral valve allograft. The elliptical patch was $50 \%$ of the size of the native leaflet and placed into a transverse incision parallel to and a few millimeters away from the annulus. ${ }^{1}$ Intraoperative transesophageal echocardiographic analysis demonstrated excellent LV function and relief of the anterior leaflet tethering with trace MR (Figure 1, $C$ and $D$ ). At 2 weeks, the patient had dramatic resolution of symptoms, and at 7 years, she is asymptomatic with mild MR.

\section{Patient 2}

A 4-month-old with poor weight gain, systolic murmur and a gallop, and a Q-wave in aVL was confirmed to have ALCAPA with bidirectional flow in the left main artery, normal LV function, and severe MR with poor central coaptation and anterior leaflet tethering. After coronary reimplantation and anterior leaflet augmentation with an allograft mitral leaflet, she was weaned easily from cardiopulmonary bypass, with excellent LV function and trace MR. At 4 years, she has normal LV function and trivial MR. 